\title{
Medication error in an extremely low birth weight infant: paracetamol overdose
}

\author{
Pablo Brener ${ }^{a, b}$, M.D., Mónica Ballardo ${ }^{a}$, M.D., Gonzalo Mariani ${ }^{a}$, M.D., and José M. Ceriani Cernadas ${ }^{a, b}$, M.D.
}

\begin{abstract}
Errors are part of human nature and are usually present in our actions. Medical errors occur quite often and can be serious. Medication errors are among the most frequent, especially in newborn infants because of the multiple steps that occur during the process of prescribing and administering drugs and because most drugs are not licensed for being used in newborn infants (off-label). The aim of this report is to describe a medication error in prescribing paracetamol for closing a patent ductus arteriosus in a preterm infant and to analyze its causes. A preterm female infant born at 27 weeks of gestational age with a birth weight of $750 \mathrm{~g}$ received paracetamol at 9 days old at a dose 20 times greater than required. The initial plasma level was $480 \mu \mathrm{g} / \mathrm{mL}$. N-acetylcysteine was administered and her clinical outcome was satisfactory. Parents were notified of the event, which was recorded in the medical record and in the electronic error reporting system of the Hospital Italiano de Buenos Aires. We consider this report as an example that we are exposed to making mistakes and should maximize precautions to improve patient safety in neonatal units.

Key words: errors, paracetamol, newborn infant, patient safety.
\end{abstract}

http:/ /dx.doi.org/10.5546/aap.2013.53

\section{INTRODUCTION}

Errors are part of human nature and are usually present in many of the activities we perform. In medicine, errors are frequent, and although they do not always lead to harmful consequences, some of them can result in serious adverse events which might eventually cause the death of the patient. There are several reasons accounting for their occurrence ranging from an inadequate culture of approaching the error to multiple deficiencies in prevention systems. ${ }^{1,2}$ Medication errors are among the most frequent, especially in newborn infants because of the multiple steps

a. Division of Neonatology, Department of Pediatrics. School of Medicine, University Institute. Hospital Italiano de Buenos Aires.

b. PatientSafety Committee, Hospital Italiano de Buenos Aires.

E-mail:

Pablo Brener Dik, M.D.: pablo.brener@hospitalitaliano.org.ar

Conflict of Interest:

None.

Received: 09-11-2012

Accepted: 10-31-2012 that occur during drug prescription and administration and to the use of drugs not licensed to be used in newborn infants (off-label).$^{3-5}$ The aim of this report is to describe a medication error in prescribing paracetamol for closing a patent ductus arteriosus in a preterm infant and to analyze its causes.

\section{CLINICAL PRESENTATION}

The preterm female infant was born at 27 weeks of gestational age, with a birth weight of $750 \mathrm{~g}$. An emergency C-section was done because of placental abruption as a consequence of maternal preeclampsia. During her clinical course she developed respiratory distress syndrome and several disorders associated with extreme prematurity: hyperglycemia, hyperbilirubinemia, anemia, sepsis, and grade 1 retinopathy.

At two days of age she had clinical signs of patent ductus arteriosus ( $3 \mathrm{~mm}$ in the ultrasound scan), with hemodynamic compromise. She received 3 doses of ibuprofen. The duct remained open, though it was smaller $(1.2 \mathrm{~mm})$ and asymptomatic. A week later she developed coagulase-negative staphylococcal sepsis and once again had hemodynamic abnormalities associated with the ductus. Paracetamol treatment was indicated.

\section{Description and semiology of the error}

Paracetamol drops concentration (strength) is $100 \mathrm{mg} / \mathrm{mL}$ and is available in a $20 \mathrm{~mL}$ bottle. The patient should have received $15 \mathrm{mg} / \mathrm{kg} / \mathrm{dose}$ every 6 hours for a total of 6 doses.

The first step of the error occurred when the doctor understood that the strength was 100 $\mathrm{mg} / 20 \mathrm{~mL}$ instead of $100 \mathrm{mg} / \mathrm{mL}$. The indication was "to administer $2 \mathrm{~mL}$ every 6 hours" and the correct one was $0.1 \mathrm{~mL}$. The second error occurred when the nurse asked, before the first dose, if this was excessive and the doctor reasserted the indication without checking the concentration. The patient received the first three doses at $266 \mathrm{mg} /$ $\mathrm{kg}$ (17.7 times greater than what she had to receive). The following morning, the nurse on duty suspected the dose was too high and consulted before administering it. When detecting the error, treatment was discontinued. 


\section{Treatment measures and clinical outcome}

The first plasma determination of paracetamol was $480 \mu \mathrm{g} / \mathrm{mL}$ (therapeutic levels are $\leq 10 \mu \mathrm{g}$ / $\mathrm{mL}$ ). The Department of Toxicology was notified and $\mathrm{N}$-acetylcysteine was indicated, initially $100 \mathrm{mg}$ and then $50 \mathrm{mg}$ until reaching 17 doses. Daily plasma levels of paracetamol were $211 \mu \mathrm{g} /$ $\mathrm{mL}, 38.4 \mu \mathrm{g} / \mathrm{mL}$, and negligible on the fourth day. Liver function tests were normal. The infant did not have any symptoms associated with the overdose, her clinical outcome was satisfactory and she was discharged at 38 weeks of adjusted gestational age.

\section{Error reporting and recording}

Parents were immediately notified that, by mistake, their daughter had received a higher dose of paracetamol, that the treatment had been discontinued and that laboratory tests would be performed to assess possible adverse events. Measurements, the consultation to the Department of Toxicology, and treatment started were recorded in the medical record. An electronic error reporting system was used to notify the adverse event to the Patient Safety Committee of the Hospital Italiano de Buenos Aires.

\section{DISCUSSION}

Non-steroidal anti-inflammatory drugs (NSAIDs) are widely used for the treatment of pain and fever in adults and children. There is, however, not enough evidence as far as their safety in newborn infants. ${ }^{6}$ There are pharmacokinetic data regarding the use of indomethacin and ibuprofen to close ductus arteriosus in preterm infants. Several studies have shown the effectiveness of these agents and, beyond current controversies, ${ }^{7}$ their use is still frequent especially when there is hemodynamic compromise. Both drugs cause adverse events, ${ }^{8,9}$ such as renal function disorders, decrease in the mesenteric and cerebral blood flow velocities, and increase of platelet aggregation; likewise, ibuprofen interferes with bilirubin-albumin binding in plasma. Recently, a series of cases where the efficacy of paracetamol to close ductus arteriosus in preterm newborn infants was published, and no adverse events were recorded. ${ }^{10}$

Paracetamol is an agent frequently involved in acute intoxication in adults, and to a lesser extent in children. ${ }^{11}$ In newborn infants, events occurring due to transplacental transfer have been reported..$^{12}$ It seems that if pregnancy ends within the first 24 hours of exposure the risk is low, regardless the maternal condition and the newborn infant care. ${ }^{13}$ The combination between a low rate of toxic metabolite production and the fast treatment might account for the sparing of our patient, even though she experienced an paracetamol level 40 times greater than the therapeutic level. In a report similar to ours, a greater damage did not occur either and early treatment with $\mathrm{N}$-acetylcysteine was also started even though the drug plasma concentration was below the proposed "treatment line". ${ }^{13}$

Additionally, activated carbon was used in this patient to decrease the absorption of the toxic agent, which is slow according to pharmacokinetic data in children. ${ }^{14}$ We did not prescribe it to our patient because the first dose had been administered over 12 hours before the error was discovered.

In a recently published systematic review about acute intoxication caused by paracetamol, it has been pointed out that due to the shortage of data it is difficult to enforce recommendations in children. ${ }^{15}$ However, $\mathrm{N}$-acetylcysteine has been used as an antidote, ${ }^{12,13}$ by adapting alignment charts of studies performed in adults. Indications suggested for the treatment can be found on $\mathrm{Ta}$ -

TABLE 1. Indications suggested for the treatment with $N$-acetylcysteine in neonatal paracetamol intoxication

\begin{tabular}{lll}
\multicolumn{1}{c}{ Transplacental intoxication } & \multicolumn{1}{c}{ Oral intoxication } \\
\hline - Potentially toxic maternal overdose & $\bullet$ & Dose intake $>150 \mathrm{mg} / \mathrm{kg}$ \\
- Maternal liver toxicity & $\bullet$ & $\begin{array}{l}\text { Four hours with levels above the treatment line } \\
\text { of the adult alignment chart }\end{array}$ \\
- Significant increase in $\mathrm{T} \beta$ compared with & $\bullet$ & Significant increase of $\mathrm{T} \beta$ compared with \\
the estimated normal $\mathrm{T} \beta$ for age & estimated normal T $\beta$ for age \\
&
\end{tabular}

Tß: plasma half-life. Arch Dis ChildFetal Neonatal 2001. 85(1):pF70-2. 
ble 1. A toxic dose would be greater than 150-200 $\mathrm{mg} / \mathrm{kg}^{13,15}$ and our patient received a higher dose with blood drug levels well beyond the "treatment line" (Figure 1).

The main objectives of the Patient Safety Committee of the Hospital Italiano de Buenos Aires are to change the traditional culture of hiding and punishing errors, by implementing a different approach from which professionals can learn from their mistakes and adequate prevention strategies can be outlined. Among other measures, staff is encouraged to understand that what is critical is to accept the error instead of denying or overlooking it, and by doing so we could learn from these bad experiences and prevent them from having a negative impact on patients. Likewise, a detailed analysis of these events, error reporting, and the implementation of safer systems are promoted. The Committee is developing a program that includes patients, parents, and family members as "partners" in error prevention initiative.

As far as the error we describe here, we wish to point out that the initial confusion about the drug concentration is common place; the main reason is that doctors rely on their memory, something that should never be done. There is an additional error which is to ignore the nurse's suggestion. This has a greater implication because the chance of preventing the initial mistake from reaching the patient was squandered.

Another aspect was to prescribe a drug rarely used in small preterm infants. In such cases, it is necessary to maximize precautions because this situation tends to result in mistakes being made.

FIGURE 1. Alignment chart for paracetamol intoxication (modified from Prescott's). Zone between lines: likely toxicity

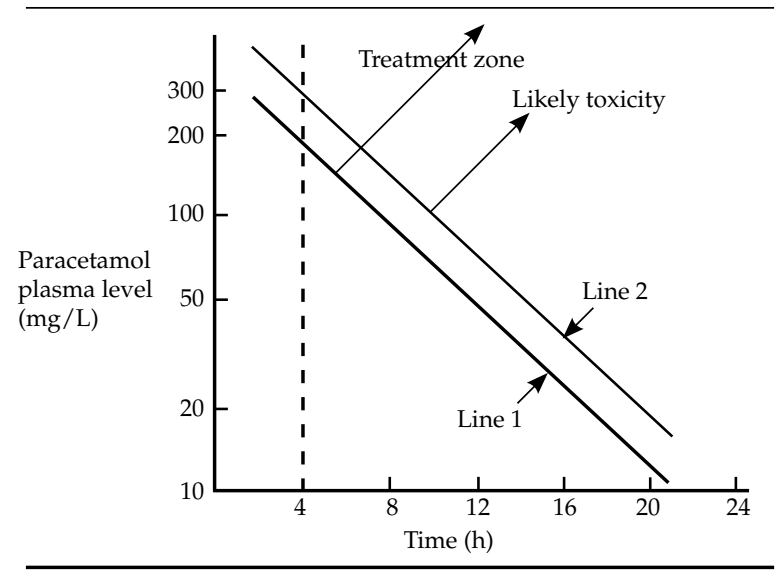

Likewise, it is questionable to prescribe a drug with little medical evidence found in medical literature to support its off-label use. This could only be justified when trying to avoid once more the use of ibuprofen, whose side effects can be harmful, especially with repeated doses. Nevertheless, only those drugs that are backed up by experience should be chosen.

As human beings, physicians and healthcare professionals are frequently exposed to making mistakes, so we hope this report is useful to learn from mistakes and to prevent them from occurring again. These events are opportunities to improve safety of care provided to newborn infants.

\section{REFERENCES}

1. Miller MR, Takata G, Stucky ER, Newspiel DR. Policy statement-principles of pediatric patient safety: reducing harm due to medical care. Pediatrics 2011;127(6):1199-210.

2. Ceriani Cernadas JM. El error en medicina: re exiones acerca de sus causas y sobre la necesidad de una actitud más crítica en nuestra profesión. Arch Argent Pediatr 2001;99(6):522-9.

3. Stavroudis TA, Miller MR, Lehmann CU. Medication errors in neonates. Clin Perinatol 2008;35(1):141-61, ix.

4. Kaushal R, Bates DW, Landrigan C, McKenna KS, et al. Medication errors and adverse drug events in pediatric inpatients. JAMA 2001;285(16):2114-20.

5. Otero P, Leyton A, Mariani G, Ceriani Cernadas JM. Medication errors in pediatric inpatients: prevalence and results of a prevention program. Pediatrics 2008;122(3):e737-43.

6. Morris JL, Rosen DA, Rosen KR. Nonsteroidal anti-in ammatory agents in neonates. Paediatr Drugs 2003;5(6):385-405.

7. BenitzWE. Patent ductus arteriosus: to treat or not to treat? Arch Dis Child Fetal Neonatal Ed 2012;97(2):F80-2.

8. Keating P, Verhagen E, Van Hoffern J, ter Horst H, et al. Effect of indomethacin infused over 30 minutes on cerebral fractional tissue oxygen extraction in preterm newborns with a patent ductus arteriosus. Neonatology 2010;98(3):232-7.

9. Vieux R, Desandes R, Boubred F, Sewama D, Guilemin F, et al. Ibuprofen in very preterm infants impairs renal function for the first month of life. Pediatr Nephrol 2010;25(2):267-74.

10. Hammerman C, Bin-Nun A, Markovitch E, Schimmel MS, et al. Ductal closure with paracetamol: a surprising new approach to patent ductus arteriosus treatment. Pediatrics 2011;128(6):e1618-21.

11. Watson WA, Litoritz TL, Rodgers GC Jr., Klein-Schwartz W, et al. 2004 Annual report of the American Association of Poison Control Centers Toxic Exposure Surveillance System. Am J Emerg Med 2005;23(5):589-666.

12. Aw MM, Dhawan A, Baker AJ, Mieli-Vergami G, et al. Neonatal paracetamol poisoning. Arch Dis C hild Fetal Neonatal Ed 1999;81:F78.

13. Isbister GK, Bucens IK, Whyte IM. Paracetamol overdose in a preterm neonate. Arch Dis Child Fetal Neonatal Ed 2001;85(1):F70-2.

14. Anderson BJ, Woollard GA, Holford NH. A model for size and age changes in the pharmacokinetics of paracetamol in neonates, infants and children. Br J Clin Pharmacol 2000;50:125-34.

15. Brok J, Buckley N, Gluud C. Interventions for paracetamol (acetaminophen) overdose. Cochrane Database Syst Rev 2006(2):CD003328. 